\title{
Creeping and structural effects in Faradaic artificial muscles
}

\author{
Laura Valero • Jose G. Martinez • Toribio F. Otero
}

Received: 23 January 2015 / Revised: 26 January 2015 / Accepted: 28 January 2015 / Published online: 10 February 2015

(C) The Author(s) 2015. This article is published with open access at Springerlink.com

\begin{abstract}
Reliable polymeric motors are required for the construction of rising accurate robots for surgeon assistance. Artificial muscles based on the electrochemistry of conducting polymers fulfil most of the required characteristics, except the presence of creeping effects during actuation. To avoid it, or to control it, a deeper knowledge of its physicochemical origin is required. With this aim here bending bilayer tape/PPy-DBSH (Polypyrrole-dodecylbenzylsulphonic acid) full polymeric artificial muscles were cycled between -2.5 and $1 \mathrm{~V}$ in aqueous solutions with parallel video recording of the described angular movement. Coulo-voltammetric (charge-potential, $Q E$ ), dynamo-voltammetric (angle-potential, $\alpha E$ ), and coulo-dynamic (charge-angle, $Q \alpha$ ) muscular responses corroborate that $10 \%$ of the charge is consumed by irreversible reactions overlapping the polymer reduction at the most cathodic potentials. In parallel, the range of the bending angular movement $\left(145^{\circ}\right)$ shifts by $15^{\circ}$ per cycle (creeping effect) pointing to the irreversible charge as possible origin of the irreversible swelling of the PPy-DBS film. Different slopes in the closed loop part of the $Q E$ identify the different reaction driven structural processes in the film: oxidation-shrinking, oxidation-compaction, reduction-relaxation, reduction-swelling, and reduction-vesicle's formation. Despite the irreversible charge fraction, the muscle motor keeps a Faradaic behaviour: described angles are linear functions of the consumed charge in the full potential range.
\end{abstract}

\footnotetext{
L. Valero · J. G. Martinez $\cdot$ T. F. Otero $(\triangle)$

Center for Electrochemistry and Intelligent Materials (CEMI),

Universidad Politécnica de Cartagena, ETSII, Paseo Alfonso XIII.

Aulario II, 30203 Cartagena, Spain

e-mail: toribio.fotero@upct.es

L. Valero

EngineeringSchool, Universidad Autónoma del Estado de México, Toluca 50000, Mexico
}

Keywords Polypyrrole $\cdot$ Artificial muscle $\cdot$ Creeping effect . Coulo-dynamics · Irreversible reaction $\cdot$ Structural electrochemistry

\section{Introduction}

The design and construction of robots for surgeon's assistance is becoming a critical issue for clinical advances. Reducing operator fatigue, improving accuracy and increasing repeatability consume most of the efforts in the area of computerintegrated surgery and robotic assistants $[1,2]$.

The simultaneous use of magnetic resonance images for the visual control of the surgeon area imposes limitations to the use of ferromagnetic materials [3]. Polymers are becoming the most suitable materials for developing two basic robotic components: actuators [4-13] and mechanical sensors [14-23]. Indeed artificial muscles based on conducting polymers work as haptic motors [24-27]: one physically uniform device fulfils both actuating and sensing requirements. From an engineering point of view, they are very robust motors due to its Faradaic nature: the position of the motor is under linear control of the consumed charge, the rate of the movement is under linear control of the applied current, and different devices with different geometry or including different masses of conducting polymers produce the same angular displacement under flow of the same charge per unit of conducting polymer mass and per unit of time [28-31].

Different families of materials constitute the named conducting polymers [32-37]. One of the remaining problems to get confidential products from artificial muscles based on conducting polymers is that some of those conducting polymer families use to develop active creeping effects. After submitting the device to a potential cycle, or to a charge cycle, the 
device doesn't recover its initial position originating a continuous displacement of the movement range on consecutive actuation cycles [38-43]. Creeping effects require quite complex self-compensation control processes to get confident products [44-50]. A more precise knowledge of the creeping effect origin may allow its elimination or an easier theoretical compensation. Not many efforts have been done in this direction. Recently, we have discovered from the voltammetric and coulo-voltammetric responses of self-supported electrodes of polypyrrole (PPy) blends with organic macro-anions $\left(\mathrm{MA}^{-}\right)$in aqueous solutions cycled up to $-2.5 \mathrm{~V}$ that most of the involved charge is consumed by the reversible film oxidation/ reduction with exchange of cations $\left(\mathrm{C}^{+}\right)$and water $(\mathrm{S})$ with the electrolyte following the general reaction (1) [28]:

$$
\begin{aligned}
& {\left[\left(\mathrm{Pol}^{0}\right)\left(\mathrm{MA}^{-}\right)_{n}\left(\mathrm{C}^{+}\right)_{n}(\mathrm{~S})_{m}\right]_{\mathrm{gel}} \rightleftarrows\left[\left(\mathrm{Pol}^{n+}\right)\left(\mathrm{MA}^{-}\right)_{n}\right]_{\mathrm{S}}} \\
& +n\left(\mathrm{C}^{+}\right)+m(\mathrm{~S})+n\left(\mathrm{e}^{-}\right)_{\text {metal }}
\end{aligned}
$$

In addition, a minor fraction of the consumed charge gives irreversible reactions at high cathodic potentials, overlapping reaction 1 backwards. Coulo-voltammetric responses allow a quantitative determination of this irreversible charge from self-supported electrodes of polypyrrole blends with dodecyl-bencylsulphonic acid (DBSH) [51] or parabenzolsulfonic acid (PBSH) [52] or from polypyrrole electrodes coating metals [53]. This irreversible open coulovoltammetric fraction is not present in responses from PPy electrodes exchanging small anions [51, 54]. Irreversible charges were attributed to the hydrogen evolution from the organic acid constituent. Here, we will investigate the evolution under potential cycling of the angular movement described by a bilayer PPy-DBS bending artificial muscles with the consumed charge from the coulo-dynamic (charge-angle) responses quantifying, simultaneously, charges consumed per cycle by reversible and irreversible reactions trying to find some correlation between the irreversible charge and creeping effects.

\section{Experimental}

The electrogeneration of the polypyrrole films, the construction of the PPy/tape bilayer muscles, the experimental electrochemical procedures, and the working conditions have been described in previous papers $[51,55]$. The PPy/tape bilayer is a full polymeric device without any metal content. The metal clamp allowing the PPy electrical contact with the working electrode (WE) plug from the potentiostat/galvanostat is located outside the electrolyte. In order to avoid uncertainties related to the possible presence of the irreversible hydrogen evolution by water electrolysis [53] at the polymer/metal clamp interface, a transversal lacquer strip is painted around the bilayer below the clamp contact to prevent the electrolyte ascension by capillarity. The bilayer muscle below the lacquer strip was immersed in the electrolyte.

All electrochemical studies were performed using an Autolab PGSTAT-100 potentiostat/galvanostat controlled by a personal computer using a (GPES ${ }^{\circledR}$ : General Purpose Electrochemical System) electrochemical software.

The electrochemical measurements were carried out in $\mathrm{LiClO}_{4}$ aqueous solutions. Parallel angular displacements of the bending muscles were recorded with a vision system using EVI-D31 SONY ${ }^{\circledR}$ digital cameras controlled by a Matrox ${ }^{\circledR}$ card and a control system programmed in $\mathrm{C}++$ for image processing in Matlab ${ }^{\circledR}$. The experimental setup is shown by Fig. 1.

\section{Results and discussion}

The bilayer muscle was submitted in $0.1 \mathrm{M} \mathrm{LiClO}_{4}$ aqueous solution to consecutive potential cycles between -2.50 and $1 \mathrm{~V}$, vs. $\mathrm{Ag} / \mathrm{AgCl}(3 \mathrm{M} \mathrm{KCl})$, at a sweep rate, $\nu$, of $6 \mathrm{mV} \mathrm{s}^{-1}$. The counter electrode was a stainless steel plate $\left(4 \mathrm{~cm}^{2}\right)$. During the initial 10 consecutive potential sweeps, the system shows rising voltammetric responses corresponding to the adaptation, after electrosynthesis, of the internal polymer film structure to the new oxidation/reduction conditions: any structural memory from the electrogeneration is erased by cycling. After those initial cycles, stationary voltammetric responses to consecutive potential cycles are obtained. Any new experimental change (i.e., potential limits, electrolyte concentration) gives stationary responses after only two consecutive cycles. This bending bilayer tape/PPy-DBS muscle (a full polymeric system, without any metal inbetween both films) translates very small PPy volume variations into large macroscopic bending angles of up to $145^{\circ}$. Figure $2 \mathrm{a}$ depicts the stationary third voltammetric response from the bilayer. Ten characteristic reference points (1 to 10) were indicated on the voltammetric response (Fig. 2a).

By voltammetric integration, the evolution of the charge (coulo-voltammetric, charge/potential or $Q / E$, responses [56]) consumed during the potential sweep by the PPy-DBS reactions is attained (Fig. 2b). Points 1 to 10 correlate those from the voltammogram (Fig. 2a). Negative charge increments indicate reduction reaction and positive increments refer to oxidation reactions.

In parallel to the voltammetric control (Fig 2a), the bending movement of the bilayer muscles was video recorded. Pictures c1 to c10 from Fig. 2 show the video frames corresponding to the bended muscle at the points 1 to 10 , respectively, from Fig. 2a, b. The angle described by the film bottom was measured from the video frame corresponding to each muscle potential as indicated in Fig. 1 [54]. Figure 2b, dotted line, 
Fig. 1 Scheme of the electrochemical cell and configuration of electrodes ( $W E$ working electrode, $C E$ counterelectrode, $R E$ reference electrode) used to follow the electrochemical behaviour of the bilayer actuator (tape/PPy-DBS). A vision system constituted by two perpendicular video-cameras was used to record and follow the angular movement in aqueous electrolyte solutions
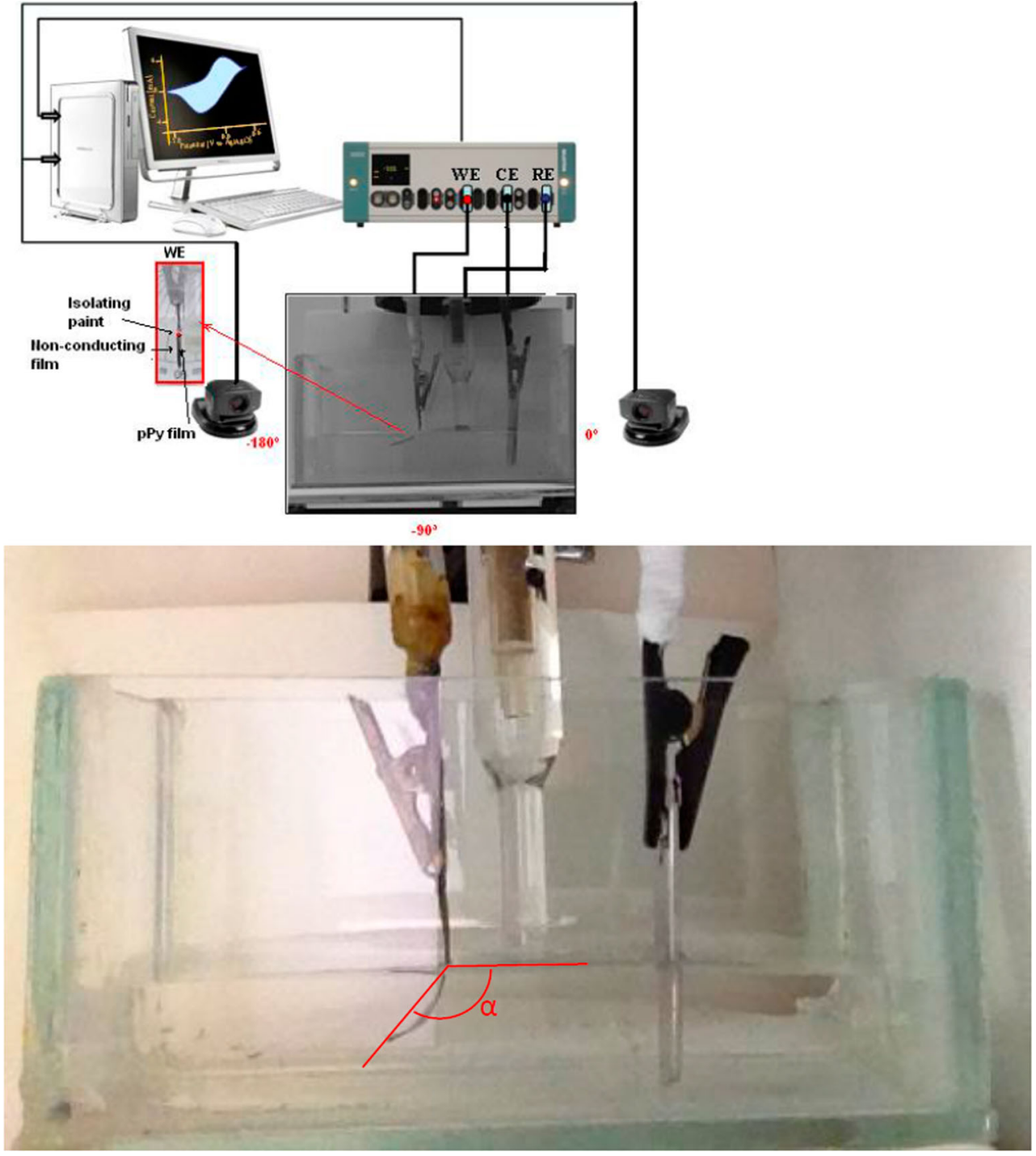

shows the dynamo-voltammetric (angle-potential) muscular response. Figure $2 \mathrm{~d}$ shows the experimental coulo-dynamic (charge-angle) muscular response. Positive angular displacements mean clockwise bending movement of the muscle bottom and negative, anticlockwise displacements. Anticlockwise bending movement is observed during the PPy-DBS oxidation from point 2 to point 6 and clockwise bending movement during the PPy-DBS reduction, from point 1 to point 2 and from point 6 to point 10 . Taking into account that the relative position of the muscle layers in the pictures is as follows: tape (left side)/PPy-DBS (right side) bending movements indicate that the PPy-DBS film shrinks by expulsion of cations and water (picture $\mathrm{c} 2$ to $\mathrm{c} 6$ ) during the positive increment of the consumed charge from point 2 to point 6 (Fig. 2b), that means during the PPy-DBS film oxidation (reaction 1 forwards). The film swells by entrance of cations and water driven by the PPy-DBS reduction, reaction 1 backwards, with negative increment of the charge (Fig. 2b) producing a clockwise movement (pictures c1 to c2 and c6 to c10).

Slopes from the coulo-voltammetric responses quantify the PPy-DBS layer reaction rate (reaction 1 forwards and backwards) at every experimental potential:

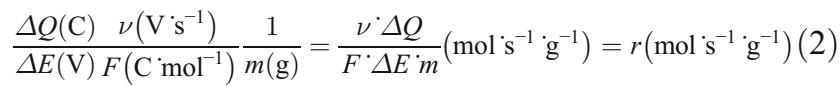

where $\Delta$ indicates variation, $F$ is the Faraday constant (96 500 $\left.\mathrm{C} \mathrm{mol}^{-1}\right)$, and $\nu\left(\mathrm{mV} \mathrm{s}^{-1}\right)$ is the experimental potential sweep rate.

Any $Q E$ slope variation identifies either, a different reaction driven structural processes in the PPy/DBS film, its potential ranges and the involved charges [51, 53]. Thus, Fig. $1 \mathrm{~b}$ corroborates that PPy/DBS film reduction-swelling (reaction 1 

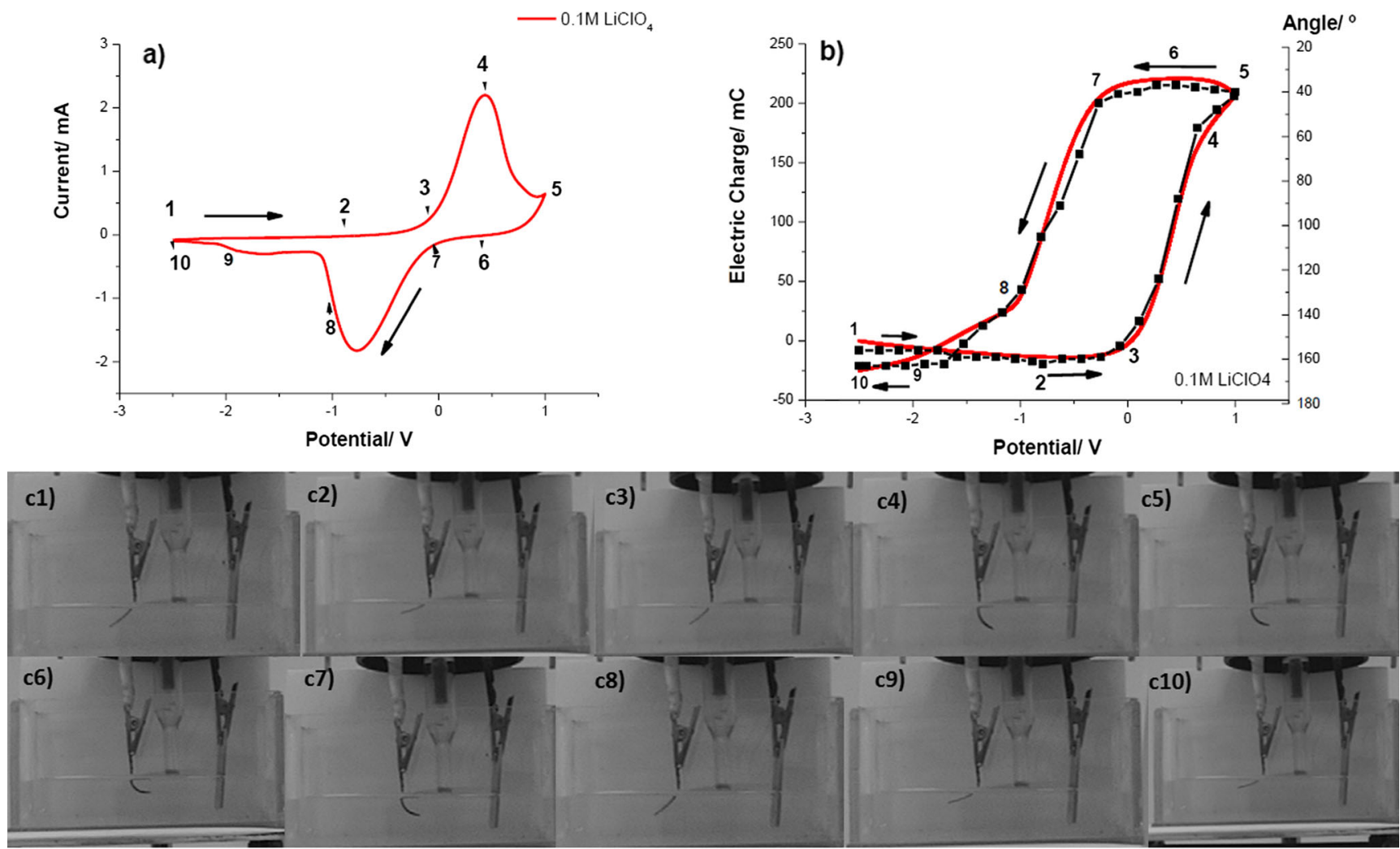

d)

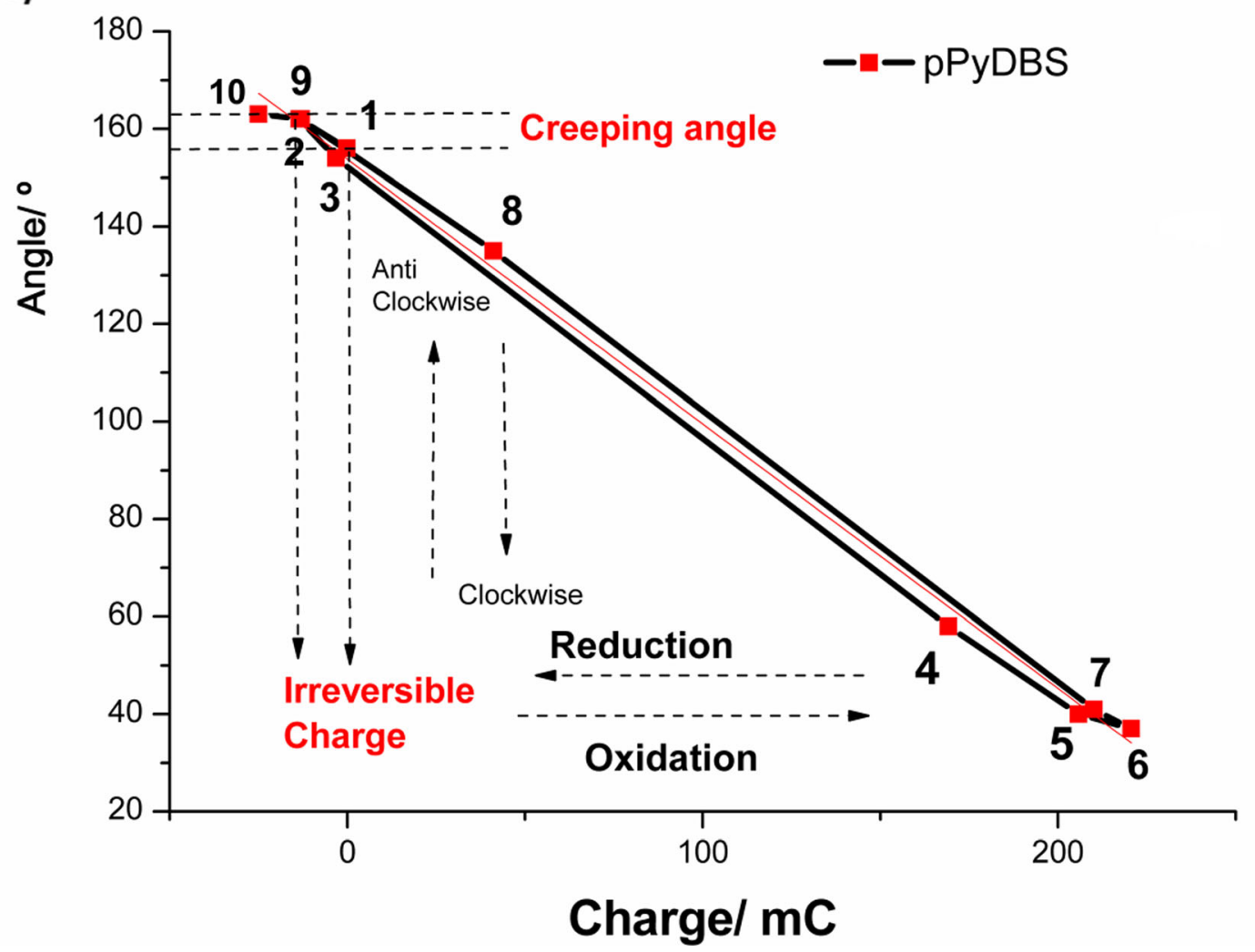


4 Fig. 2 a Stationary voltammetric response from a tape/PPy-DBS bilayer muscle submitted to consecutive potential sweeps between -2.50 and $1.0 \mathrm{~V}$ at $6 \mathrm{mV} \mathrm{s}^{-1}$ in $0.1 \mathrm{M} \mathrm{LiClO}_{4}$ aqueous solution. b Coulo-voltammetric response obtained by integration of the voltammogram, and parallel evolution of the angle described (dots) by the muscle: dynamo-voltammetric response. c Pictures ( $c 1$ to $c 10$ ) show the bending position of the muscle corresponding to the points 1 to 10 from Fig. 2a, b, d. d Evolution of the angular displacement of the muscle with the consumed charges, coulo-dynamic response, along the potential cycle

backwards) goes on between the initial potential (point 1) and the $Q E$ minimum, point 2. There, the film oxidation-shrinking (from point 2 to 4 ) and its subsequent oxidationconformational packing (from point 4 to 6 ) with expulsion of cations and water (reaction 1, forwards) takes place. The separation point between oxidation-shrinking and oxidationcompaction regions is the closing potential.

After the $Q E$ maximum, the film reduction starts with a very slow reduction-relaxation process (points 6-7), followed by the fast reduction-swelling process (point 7 to 8 ) and then a slow reduction process (points 8 to 10) attributed to the formation of vesicles (water and ions surrounded by a DBS layer) $[33,57-59]$ in the film, similar to those observed in colloidal dispersions of the surfactant [60].

The reduction charge (Fig. 1b full line) always drives the volume increment of the PPy-DBS film due to the entrance of cations and water giving a parallel angular displacement (Fig. 1b, dotted line).

The slow reduction process at cathodic potential (from 9 to 10 and from 1 to 2) overlaps the parallel presence of an irreversible process, revealed by the open part of the $Q V$ response (Fig. 1b) and attributed to the DBSH reduction with slow hydrogen evolution $[51,53]$. The charge difference between the initial and final points of the $Q E$ response at the cathodic potential limit (the open $Q E$ part) is the irreversible charge consumed by the irreversible and slow hydrogen evolution $[51,53]$. The charge difference between the $Q E$ closed loop maximum and its minimum is the reversible film oxidation/ reduction (reaction 1) charge and, considering the different slopes, the charge involved by each of the reaction driven structural processes.

For those bilayer muscles constituted by CPs which coulovoltammetric responses doesn't show any irreversible reaction in a similar potential ranges a linear coulo-dynamic $(Q / \alpha)$ response is attained, proving the Faradaic origin of the movement in the full potential range [29-31, 54]. Here despite the presence of some reduction irreversible charge the coulodynamic response $(Q / \alpha)$, Figure 2 d, corroborates the faradic (reaction 1) nature of the motor movement in the full potential range:

$\alpha=\alpha_{0}+k Q$

where $\alpha$ (degrees) is the described angle, $\alpha_{0}$ is the initial position of the muscle, $Q(\mathrm{C})$ is the consumed charge and $k$ (degrees $\mathrm{C}^{-1}$ ) is the coulodynamic constant (the empirical slope from Fig. 2d) of the system conducting polymer-tapeelectrolyte. Through reaction 1 the charge controls the number $(n)$ of monovalent cations moving into the film during reduction or expulsed during oxidation: $n=Q / \mathrm{e}^{-}$, where $e^{-}$represents the electron charge. Every new cation moving into the film membrane drives the entrance of a defined number of water molecules for osmotic balance [61-65]. The result is that the charge controls the PPy-DBS film volume variation, the concomitant variation of the generated stress gradient across the bilayer muscle, and the correlated amplitude of the described angle.

The most significant aspect from Fig. $2 b$ and $2 d$ is the presence of both, a cathodic irreversible reduction charge of $25 \mathrm{mC}$, versus a total reversible charge of $252 \mathrm{mC}$, and an irreversible clockwise (related to the muscle position at the beginning of the potential sweep: point 1 to point 10 distance) bending shift of $14^{\circ}$ (creeping angle) versus a total described angle of $145^{\circ}$. As a consequence of the creeping effect after four consecutive cycles, each producing a creeping shift of $14^{\circ}$, the reduced muscle's bottom at the end of the cathodic sweep moved outside the solution. Under similar conditions, bilayer muscles constituted by conducting polymers without irreversible reaction doesn't present, according with the literature [30, 31, 54], creeping effects. Those results point to the irreversible charge as origin (or one of the possible components) of the creeping effect in PPy-DBS films. This charge originates the irreversible hydrogen evolution from DBSH component and a parallel irreversible film swelling per potential cycle, as deduced from the creeping angle.

Once identified, the possible origin of the creeping effect different experimental approaches will be investigated during subsequent works in order to compensate physical (creeping) and chemical (local concentrations) effects of the creeping driven irreversible reaction.

\section{Conclusion}

Coulo-voltammetric (charge-potential) responses from -2.5 to $1 \mathrm{~V}$ from a full organic tape/PPy-DBS bilayer muscle in aqueous solutions indicates the presence of parallel slow irreversible reactions at high cathodic potential overlapping the reversible reduction of the PPy layer. The charge spent by the irreversible process is around $10 \%$ of the coulo-voltammetric charge. A constant angle of $145^{\circ}$ is described (go and back) per cycle but shifting $14^{\circ}$ clockwise per cycle (creeping effect). The reversible, per cycle, film oxidation/reduction charge measured form the coulo-voltammetric-closed loop is $252 \mathrm{mC}$ per cycle. The irreversible charge per cycle obtained from the $Q E$ open part is $25 \mathrm{mC}$ per cycle. The clockwise creeping displacement per cycle points to the presence of an irreversible PPy-DBS swelling linked to the irreversible 
hydrogen evolution from the HDBS component. The different slopes from the $Q E$ responses corroborate the presence of the reaction driven structural changes: oxidation-shrinking, oxidation-compaction, reduction-relaxation, reduction-swelling, and reduction-vesicle formation. The coulo-dynamic $(Q / \alpha)$ response of the muscle corroborates that, despite the presence of the irreversible hydrogen evolution, the muscle still behaves as a Faradaic polymeric motor: the described angle follows a linear dependence of the consumed charge up to $-2.5 \mathrm{~V}$.

Acknowledgments The authors acknowledge financial support from the Spanish Government, Projects MAT2011-24973, and from the Mexican Government CONACYT and the Universidad Autónoma del Estado de México. J.G. Martinez acknowledges to the Spanish Education Ministry for a FPU grant (AP2010-3460).

Open Access This article is distributed under the terms of the Creative Commons Attribution License which permits any use, distribution, and reproduction in any medium, provided the original author(s) and the source are credited.

\section{References}

1. Taylor RH (2006) A perspective on medical robotics. Proc IEEE 94: 1652-1664

2. Taylor RH, Menciassi A, Fichtinger G, Dario P (2008) Medical robotics and computer-integrated surgery. In: Prof BS, Prof OK (eds) Springer handb. robot. Springer Berlin Heidelberg, Berlin, pp 11991222

3. Stoianovici D, Kim C, Srimathveeravalli G et al (2014) MRI-safe robot for endorectal prostate biopsy. IEEE/ASME Trans Mechatron 19:1289-1299

4. Otero TF, Angulo E, Rodríguez J, Santamaría C (1992) Electrochemomechanical properties from a bilayer: polypyrrole/ non-conducting and flexible material-artificial muscle. J Electroanal Chem 341:369-375

5. Pei Q, Inganas O (1992) Conjugated polymers and the bending cantilever method - electrical muscles and smart devices. Adv Mater 4: 277-278

6. Smela E (2003) Conjugated polymer actuators for biomedical applications. Adv Mater 15:481-494

7. Jager EWH, Smela E, Inganas O (2000) Microfabricating conjugated polymer actuators. Science 290:1540-1545

8. Mirfakhrai T, Madden JDW, Baughman RH (2007) Polymer artificial muscles. Mater Today 10:30-38

9. Long Y-Z, Li M-M, Gu C et al (2011) Recent advances in synthesis, physical properties and applications of conducting polymer nanotubes and nanofibers. Prog Polym Sci 36:1415-1442

10. Das TK, Prusty S (2012) Review on conducting polymers and their applications. Polym-Plast Technol Eng 51:1487-1500

11. Otero TF, Grande H, Rodriguez J (1996) Reversible electrochemical reactions in conducting polymers: a molecular approach to artificial muscles. J Phys Org Chem 9:381-386

12. Okuzaki H, Suzuki H, Ito T (2009) Electrically driven PEDOT/PSS actuators. Synth Met 159:2233-2236

13. Okuzaki H, Funasaka K (1999) Electrically driven polypyrrole film actuator working in air. J Intell Mater Syst Struct 10:465-469
14. Tjahyono AP, Aw KC, Travas-Sejdic J (2012) A novel polypyrrole and natural rubber based flexible large strain sensor. Sensors Actuators B Chem 166:426-437

15. Wallace GG, Spinks GM, Kane-Maguire LAP (2008) Conductive electroactive polymers: intelligent polymer systems, 3rd edn. CRC Press, London

16. Li Y, Cheng XY, Leung MY et al (2005) A flexible strain sensor from polypyrrole-coated fabrics. Synth Met 155:89-94

17. Xue P, Tao XM, Tsang HY (2007) In situ SEM studies on strain sensing mechanisms of PPy-coated electrically conducting fabrics. Appl Surf Sci 253:3387-3392

18. Takashima W, Hayasi K, Kaneto K (2007) Force detection with Donnan equilibrium in polypyrrole film. Electrochem Commun 9: 2056-2061

19. Wu Y, Alici G, Madden JDW et al (2007) Soft mechanical sensors through reverse actuation in polypyrrole. Adv Funct Mater 17:32163222

20. Alici G, Spinks GM, Madden JD et al (2008) Response characterization of electroactive polymers as mechanical sensors. IEEE/ASME Trans Mechatron 13:187-196

21. Shoa T, Madden JDW, Mirfakhrai T et al (2010) Electromechanical coupling in polypyrrole sensors and actuators. Sensors Actuators A Phys 161:127-133

22. John SW, Alici G, Spinks GM et al (2009) Towards fully optimized conducting polymer bending sensors: the effect of geometry. Smart Mater Struct 18:085007

23. Spinks GM, Wallace GG, Liu L, Zhou D (2003) Conducting polymers electromechanical actuators and strain sensors. Macromol Symp 192:161-169

24. Otero TF, Martinez JG Physical and chemical awareness from sensing polymeric artificial muscles. Experiments and modeling. Prog Polym Sci. doi:10.1016/j.progpolymsci.2014.09.002

25. Martinez JG, Otero TF (2014) Mechanical awareness from sensing artificial muscles: experiments and modeling. Sensors Actuators B Chem 195:365-372

26. Otero T, Cortes M (2003) Artificial muscles with tactile sensitivity. Adv Mater 15:279-282

27. Otero TF, Cortes MT (2003) A sensing muscle. Sensors Actuators B Chem 96:152-156

28. Otero TF, Martinez JG, Arias-Pardilla J (2012) Biomimetic electrochemistry from conducting polymers. A review: artificial muscles, smart membranes, smart drug delivery and computer/neuron interfaces. Electrochim Acta 84:112-128

29. Conzuelo LV, Arias-Pardilla J, Cauich-Rodríguez JV et al (2010) Sensing and tactile artificial muscles from reactive materials. Sensors 10:2638-2674

30. Otero TF, Cortes MT (2004) Artificial muscle: movement and position control. Chem Commun 284-285

31. Otero TF, Sansiñena JM (1997) Bilayer dimensions and movement in artificial muscles. Bioelectrochem Bioenerg 42:117-122

32. Otero TF (1999) Conducting polymers, electrochemistry, and biomimicking processes. In: White RE, Bockris JO, Conway BE (eds) Mod. Asp. Electrochem. Springer US, New York, pp 307-434

33. Otero TF (2013) Biomimetic conducting polymers: synthesis, materials, properties, functions, and devices. Polym Rev 53:311-351

34. Heeger AJ (2001) Semiconducting and metallic polymers: the fourth generation of polymeric materials. J Phys Chem B 105:8475-8491

35. Guernion NJL, Hayes W (2004) 3-and 3,4-substituted pyrroles and thiophenes and their corresponding polymers - a review. Curr Org Chem 8:637-651

36. Fabre B, Simonet J (1998) Electroactive polymers containing crown ether or polyether ligands as cation-responsive materials. Coord Chem Rev 178:1211-1250

37. Malinauskas A (2004) Self-doped polyanilines. J Power Sources 126: 214-220 
38. Smela E, Lu W, Mattes BR (2005) Polyaniline actuators-part 1. PANI(AMPS) in HCl. Synth Met 151:25-42

39. Sendai T, Suematsu H, Kaneto K (2009) Anisotropic strain and memory effect in electrochemomechanical strain of polypyrrole films under high tensile stresses. Jpn J Appl Phys 48:051506

40. Kiefer R, Bowmaker GA, Cooney RP et al (2008) Cation driven actuation for free standing PEDOT films prepared from propylene carbonate electrolytes containing $\mathrm{TBACF}(3) \mathrm{SO}(3)$. Electrochim Acta 53:2593-2599

41. Madden JD, Rinderknecht D, Anquetil PA, Hunter IW (2007) Creep and cycle life in polypyrrole actuators. Sensors Actuators A Phys 133:210-217

42. Naumann T, Stommel M (2012) Influence of hydrostatic pressure and volumetric strain on the mechanical long term behavior of polymers. J Polym Eng 32:327-333

43. Fuchiwaki M, Takashima W, Kaneto K (2001) Comparative study of electrochemomechanical deformations of poly(3-alkylthiophene)s, polyanilines and polypyrrole films. Jpn J Appl Phys Part 1-Regul Pap Short Notes Rev Pap 40:7110-7116

44. Moheimani SOR (2008) Invited review article: accurate and fast nanopositioning with piezoelectric tube scanners: emerging trends and future challenges. Rev Sci Instrum 79:071101

45. Wang X, Pommier-Budinger V, Reysset A, Gourinat Y (2014) Simultaneous compensation of hysteresis and creep in a single piezoelectric actuator by open-loop control for quasi-static space active optics applications. Control Eng Pract 33:48-62

46. Gu G-Y, Zhu L-M (2013) Motion control of piezoceramic actuators with creep, hysteresis and vibration compensation. Sensors Actuators A Phys 197:76-87

47. Yao Q, Alici G, Spinks GA (2008) Feedback control of tri-layer polymer actuators to improve their positioning ability and speed of response. Sensors Actuators A Phys 144:176-184

48. Hao L, Li Z (2010) Modeling and adaptive inverse control of hysteresis and creep in ionic polymer-metal composite actuators. Smart Mater Struct 19:025014

49. Chi Z, Xu Q (2014) Recent advances in the control of piezoelectric actuators. Int J Adv Robot Syst 11:11

50. Pesotski D, Janocha H, Kuhnen K (2010) Adaptive compensation of hysteretic and creep non-linearities in solid-state actuators. J Intell Mater Syst Struct 21:1437-1446

51. Otero TF, Martinez JG, Fuchiwaki M, Valero L (2014) Structural electrochemistry from freestanding polypyrrole films: full hydrogen inhibition from aqueous solutions. Adv Funct Mater 24:1265-1274

52. Fuchiwaki M, Otero TF (2014) Polypyrrole-para-phenolsulfonic acid/tape artificial muscle as a tool to clarify biomimetic driven reactions and ionic exchanges. J Mater Chem B 2:1954-1965
53. Otero TF, Alfaro M, Martinez V et al (2013) Biomimetic structural electrochemistry from conducting polymers: processes, charges, and energies. Coulovoltammetric results from films on metals revisited. Adv Funct Mater 23:3929-3940

54. Otero TF, Martinez JG (2014) Ionic exchanges, structural movements and driven reactions in conducting polymers from bending artificial muscles. Sensors Actuators B Chem 199:2730

55. Valero L, Arias-Pardilla J, Cauich-Rodríguez J et al (2011) Characterization of the movement of polypyrroledodecylbenzenesulfonate-perchlorate/tape artificial muscles. Faradaic control of reactive artificial molecular motors and muscles. Electrochim Acta 56:3721-3726

56. Grande H, Otero TF (1998) Intrinsic asymmetry, hysteresis, and conformational relaxation during redox switching in polypyrrole: a coulovoltametric study. J Phys Chem B 102:7535-7540

57. West BJ, Otero TF, Shapiro B, Smela E (2009) Chronoamperometric study of conformational relaxation in PPy(DBS). J Phys Chem B 113:1277-1293

58. Wernet W, Monkenbusch M, Wegner G (1985) On structure and properties of polypyrrole alkyl-sulf(on)ates. Mol Cryst Liq Cryst 118:193-197

59. Wernet W, Monkenbusch M, Wegner G (1984) A new series of conducting polymers with layered structure-polypyrrole normalalkylsulfates and normal-alkylsulfonates. Makromol Chem Rapid Commun 5:157-164

60. Lee H-H, Yamaoka S, Murayama N, Shibata J (2007) Dispersion of $\mathrm{Fe} 3 \mathrm{O} 4$ suspensions using sodium dodecylbenzene sulphonate as dispersant. Mater Lett 61:3974-3977

61. Otero TF, Martinez JG (2012) Artificial muscles: a tool to quantify exchanged solvent during biomimetic reactions. Chem Mater 24: 4093-4099

62. Otero TF, Martínez JG, Zaifoglu B (2013) Using reactive artificial muscles to determine water exchange during reactions. Smart Mater Struct 22:104019

63. Valero L, Otero TF, Martínez JG (2014) Exchanged cations and water during reactions in polypyrrole macroions from artificial muscles. ChemPhysChem 15:293-301

64. Bay L, Jacobsen T, Skaarup S, West K (2001) Mechanism of actuation in conducting polymers: osmotic expansion. J Phys Chem B Chem 105:8492-8497

65. Jafeen MJM, Careem MA, Skaarup S (2012) A novel method for the determination of membrane hydration numbers of cations in conducting polymers. J Solid State Electrochem 16: $1753-1759$ 